\title{
Production of handicrafts, wares and novelty items from coconut wood, fronds and coconut fruit residues
}

\author{
Luisito J. Penamora ${ }^{1}$
}

\begin{abstract}
The production of handicrafts, wares and novelty items utilizing small and short pieces of coconut wood, fronds and shell is a highly feasible and viable option to derive income from coconut residues and other cellulosic materials found in coconut plantation.

Handicrafts and novelty items from coconut fronds, wood and other residues are potential export commodities that can compete with other indigenous products because of their unique appearance and quality. Given the tremendous amount of readily available raw materials from coconut farms, a manufacturer is assured of a sustainable operation.

Property tests conducted on coconut frond's structure have shown its fitness to be used as alternative material to some light wood species. It has an average specific gravity (sg) value of 0.20 and mean volumetric shrinkage of $63 \%$. Effectual use investigations of coconut fronds and coconut fruit residues on machining, treatment, gluing properties and finishing requirements are all satisfactory. With the use of a technique, "mix and match", they can be skillfully combined with coconut wood to make good finished products. Skills, creativity and craftsmanship on the part of the people involved in the job were crucial aspects of the production.

Some of the crafts and novelty items produced were; all-purpose trays, trophies, flower vases and candle holders, chairs, dividers, plant boxes, table and dresser to name a few. The production cost estimates was at minimum with about 50-60 percent cheaper than the traditional materials such as wood.
\end{abstract}

Key words: Coconut fronds, coconut fruit residues, handicrafts and novelty items, "mix and match" technique

${ }^{1}$ Division Chief, Timber Utilization Division, PCA-Zamboanga Research Center, P.O. Box 356, San Ramon, Zamboanga City, Philippines, 7000. e-mail: pca_zrc@pldtdsl.net, louie.penamora@yahoo.com 


\section{Introduction}

Processing and utilization of coconut tree and its parts into various forms of finished products is not new at all. In fact the reason why it is called the "Tree of Life" is because of the countless possibilities by which it can be utilized for food and non-food products. While the economic importance being attached to coconut is attributed to its major product, i.e. copra, its full potential as ligno-cellulosic material for other vital usage has not been fully realized.

The current concern for the utilization of coconut farm residues and the renewed interest to develop and promote new high-value added coconut products including coconut wood has set off several product development activities to bring about large scale utilization of coconut waste materials. In this regard, comprehensive $\mathrm{R}$ and $\mathrm{D}$ activities on the utilization of coconut fibrous residues for the development of housing materials, wares and handicrafts from wood, husk, shell, fronds, midribs, petioles and other cellulosic portions of coconut tree was done.

Given the tremendous amount of raw material that can be obtained from coconut plantations, appropriate techniques must be developed to make use of these resources. Estimates showed that a fully bearing coconut plantation could generate 12.75 tons of coconut residues per hectare per year. Of these, the petiole accounts for $50.12 \%$ of the total weight with $18.35 \%$ for leaves including midribs, $14.28 \%$ for husk, $10.98 \%$ for peduncle, $4.47 \%$ for spathe and $1.80 \%$ for leafsheath (Palomar, et.al., 2000)

The opportunity for utilization and development of value-added products from coconut is never-ending. There are million possibilities that can be made out of it depending on one's creativity and skills. Arboleda, 1993, pointed out the vast opportunities turn coconut wastes and residues into useful products that could benefit many sectors of the local industry. This would have provided employment to many and would have offer readily alternative source of livelihood. A review conducted by Magat, 1995 strongly indicates the enormous potential of coconut waste materials such as husk to become high-value products with a market-driven demand. Among the traditional industrial uses include furniture and building interiors, handicrafts and household items, fiberboards and application in agricultural and horticultural uses. This would certainly benefit the coconut farmers who would be assured of additional source of income.

This paper illustrates some options and opportunities in processing and utilization of mature coconut fronds, wood, coconut fruit residues and other parts of the coconut palm structure for the manufacture of handicrafts, wares, novelty items, and other industrial and economic products either as the main or as a component raw material.

\section{Materials and methods}

\section{Coconut fronds}

\section{a. Physical Properties of Cocofronds}

To establish a guide in the effectual usage of coconut fronds for various products, either singly or in combination with the woody parts of coconut tree, the basic physical properties of coconut fronds, such as density and specific gravity, moisture content and shrinkage characteristics were initially determined.

The effectual uses of the material in machining, sanding and gluing, mixing and matching of structural components and finishing requirements to enhance aesthetic value and effective shelf life of the finished products were also determined.

\section{b. Manufacture of handicrafts and novelty items and other products from fronds}

New products from coconut fronds were designed fabricated and tested using matured and air-dried coconut fronds as main 
component. The raw materials were used in pure form or in combination with coconut wood materials. Different products such as plant boxes, chairs, tables, stools, cabinets and dividers were designed and fabricated using coconut fronds with coco wood frames as the major skeletal support. The finished products were tested to determine their performance in service conditions.

Mature and dried coconut fronds were collected and air dried to equilibrium moisture content of about 17-18\% in 2 to 3 weeks under shed and subsequently machined and assembled into finished products. Parts of fronds were selected based on the uses. The denser parts of the fronds were obtained in the rachis portion of the fronds, purposely to be used as seat of furniture or in components that require loads. Nails and glues were used as fasteners and split rattan was used to bind the sliced fronds to the cocowood frame. The raw materials were properly dried and treated with "Timbor", an anti-wood boring insect preservative prior to assembly and finishing.

\section{Coconut Fruit Residues}

Newly harvested mature coconut fruits with age of about 11-12 month old were sliced to extract the coconut meat with the use of a sharp narrow band saw. After the removal of meat, the residues were dried to equilibrium moisture content by hot air drying in an enclosed chamber maintained at $40^{\circ} \mathrm{C}$. Sanding operation was done both manually and mechanically using the machine sander. With the use of "mix and match" technique, different products were designed and fabricated. The products were assembled using fasteners such as dowels and glue and finished with a variety of sealants and topcoats.

\section{Results and discussion}

\section{Physical properties of mature coconut fronds}

The coconut frond consists of a petiole, leaflets, and a main rachis. The leaflets consist of the lamina and a central pinna or midrib. The mature coconut frond is a woody material that has an average volume of $3.80 \mathrm{bd} \mathrm{ft}$ with a usable wood recovery of $23 \%$. The estimated utilizable wood volume of coconut fronds generated from one hectare plantation is about 1,048 bd ft per year.

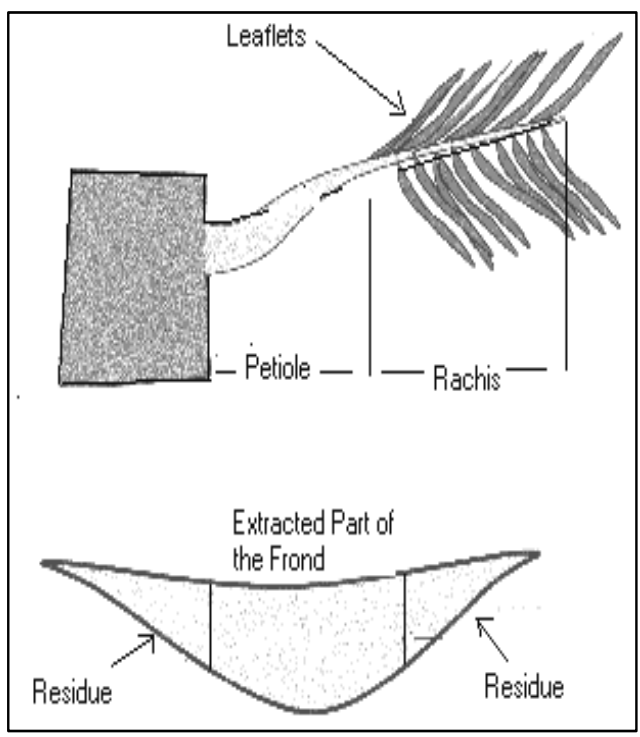

The average specific gravity of coconut fronds (petiole and rachis) is 0.20 . On the other hand, the shrinkage values are lower for rachis compared with that of the petiole (Table 1 and Figure 1.). The shrinkage value is lesser for the tapering rachis compared with that of the petiole due to the smaller number, more scattered (less dense per unit area) vascular bundles in the petiole than in the rachis (more dense). This also showed that high shrinkage

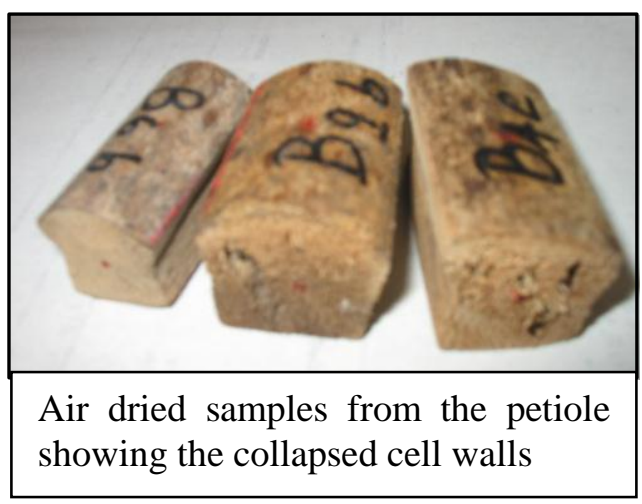




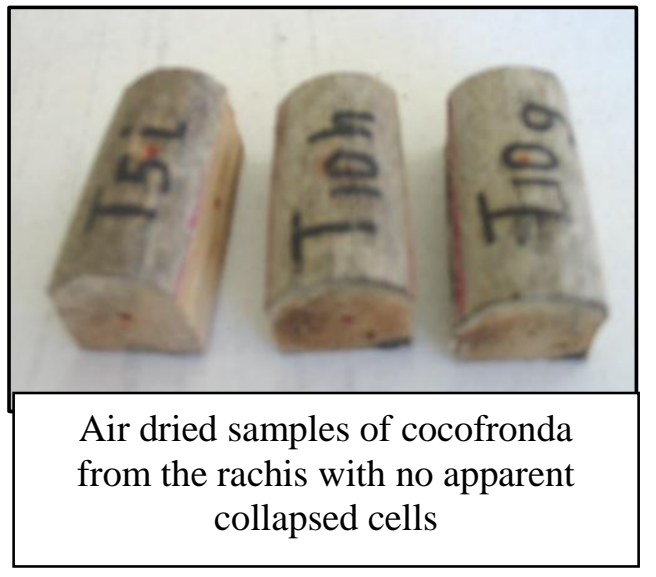

Table 1. Comparative physical data for the 2 different segment of coconut fronds*

\begin{tabular}{|l|c|c|c|c|c|}
\hline \multirow{2}{*}{ Segment } & \multirow{2}{*}{$\begin{array}{c}\text { Specific } \\
\text { Gravity }\end{array}$} & \multicolumn{4}{|c|}{ Shrinkage Value (\%) } \\
\cline { 3 - 6 } & & Tangential & Radial & Longitudinal & Volumetric \\
\hline Petiole & 0.19 & 48.13 & 42.68 & 0.76 & 69.44 \\
\hline Rachis & 0.22 & 38.93 & 31.16 & 0.58 & 57.25 \\
\hline
\end{tabular}

value given by petiole is actually a manifestation of severe collapse of the thin cell walls that occurred during drying process, a similar characteristics evident in low density portion of coconut wood. The more dense assembly of the vascular bundles in rachis makes it stronger than the petiole in addition to the varying unique cross section cleavage and shape of the frond itself.

These properties of coconut frond provide a sound basis in considering their application as structural insulators, core materials, panels, nets and buoys, swimming aids, sandwich panels, furniture and novelty items.

\section{Design and fabrication of products}

Drying of coconut fronds for about 3 to 4 weeks under shed
Different products such as plant boxes, chairs, tables, stools, cabinets and dividers were designed and fabricated using coconut fronds as the main components and coconut wood as skeletal frames. The step by step procedure in the processing of the fronds is presented below:

1. Collect the mature fronds at the time of harvesting the nuts. Do not left fronds in the field because, like any wood species, the frond is attacked by wood boring insects and fungi that abound in a coconut plantation. These pests inflict serious damage to all parts of the frond thus reducing their strength and visual value.

2. After gathering, remove leaflets and allow them to dry naturally under shed. Drying time ranges from 3 to 4 weeks depending on weather conditions.

3. Machine, rip and cut the materials with manual or motor driven saws. It could also be planed, polished, machined and assembled using common wood working tools. Use it singly in making picture frames but for added strength, it is necessary to combine it with light woody materials or thin plywood (e.g., 1/8") when used in furniture, novelty items and other fixtures

4. Prior to assembly, apply anti-wood-boring insect preservatives like "Timbor, Cuprinol and Solignum on the dried materials. This is necessary to avert incidence of infestation by wood boring insects in service. A suitable mixture of 
Cord 2007, 23 (2)

Fig 1. Process flow in the production of handicrafts and novelty items

oil-basec from coconut fronds

Ig of varnish or

light oil sum as nesuscenc van ue uscu at o. 1 kerosene: preservative ratio.

5. Assemble the products using nails and common white glues. Split rattan is used as mechanical binder for added strength and aesthetic purposes.

6. Prior to finishing, manually sand the surfaces. This is followed by the application of two to three coats of lacquer sanding lival giuss lacyull.

7. Some of the suitable packaging materials are paperboards molded and fashioned into rigid boxes.

\section{B. Coconut Fruit Residues}

The residues of coconut fruit are the parts of matured coconuts which are left behind after the removal of the meat for copra. These parts are 
usually thrown out and burned by the farmers but with the use of appropriate technology, these byproducts can be converted into fine handicrafts and novelty items.

Coconut fruit residues as raw materials have distinct characteristics that can be utilized to make good products specially when combined or matched with other materials such as cocowood. The varying nut shapes, color and texture of coconut fruit provide a wide range of possibilities by which they can be designed and fabricated into a particular type of product.

Coconut fruit residues, as raw materials are physically suited for the manufacture of handicrafts and novelty items, but it requires good amount of skills and attention in order to design, machine and finish high-quality products. Depending on one's skill, the style of the finished product vary according to the nut shape, color and texture of the surrounding fibrous layer. With use of a technique called "mix and match" method, the physical qualities of coconut fruit residues can be complemented with coconut wood. Different varieties of coconut exhibit varying shapes and characteristics that influence the outcome of a particular finished product.

\section{Manufacturing Process}

1. Using a sharp narrow band saw (2" wide), cut/slice the mature coconut fruit and scoop out the meat for copra. Round coconut fruits such as the variety called "Kiamba" green dwarf is suitable for making coco clock while a dwarf variety called "Mangipod" is a good material for making all-purpose trays.

2. Dry the materials in a low temperature kiln dryer to about $10 \%$ to $12 \%$ moisture content. Drying time is from six to eight hours in kiln while it takes two to three days in open air condition.

3. Polish the surfaces of the material by machine sanding. Use a motor-driven disc sander to smoothen surface followed manual sanding.

4. Assemble the machined and sanded parts to make a product. Glues like PVA or Urea Formaldehyde and wooden dowels are good fasteners to assemble the product. Nails or any metal fasteners do not easily hold the husk.

5. In finishing, husk takes-in a great quantity of finishing materials hence the surface must be sealed with lacquer sanding sealer or PVA emulsion glue prior to application of topcoat. Among the suitable top

6. Coating materials are clear gloss lacquer, polyurethane and varnish. Finishing can be accomplished with the aid of brush in three to four coatings. 


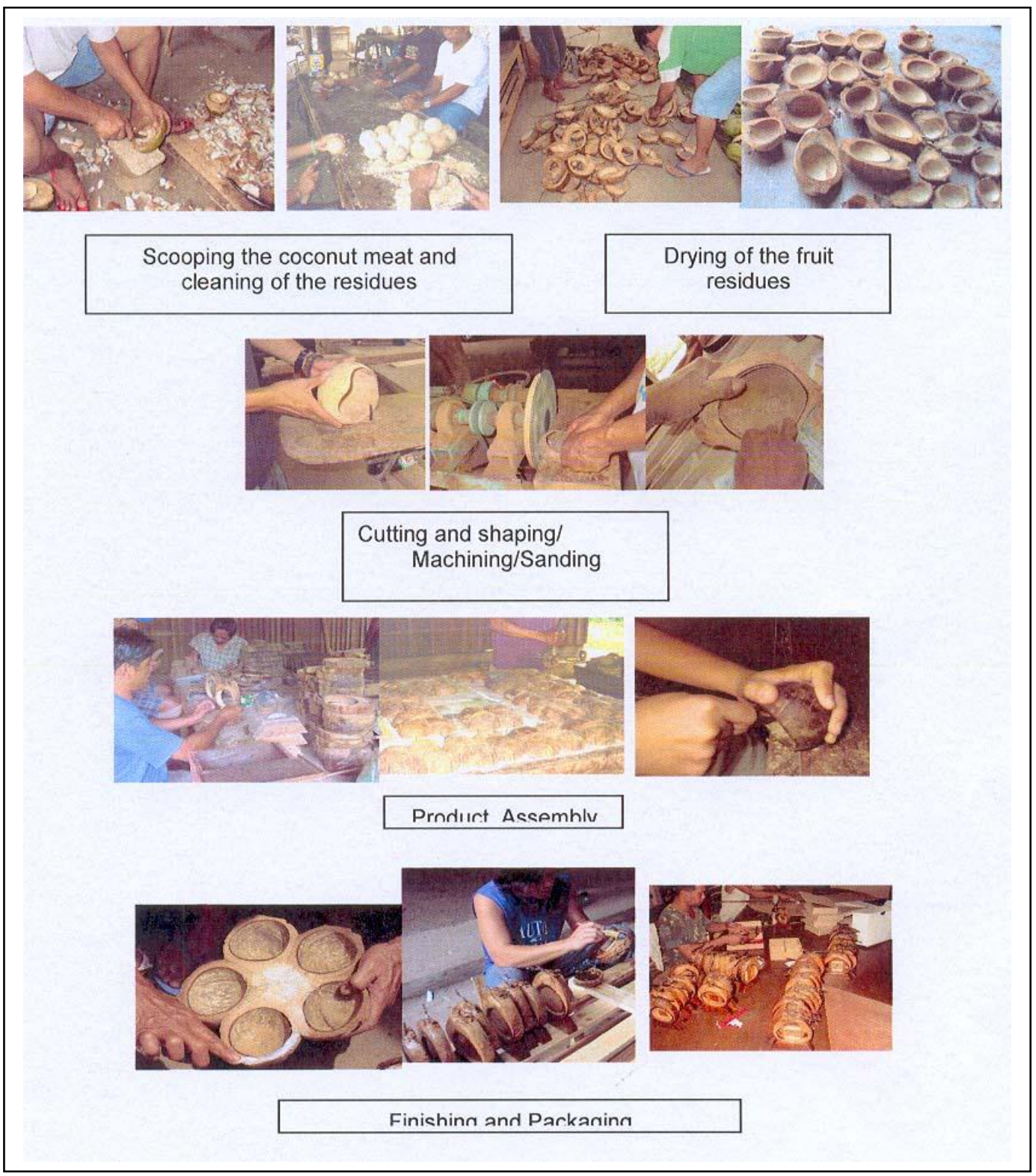

Fig 2. Process flow on the production of handicrafts from coconut fruit 


\section{Conclusion}

This technology has opened up new avenues in the usefulness of coconut fronds, wood and coconut fruit residues as raw materials for the manufacture of wares and handicraft items. With the appropriate techniques, these materials can be processed to produce attractive and exportable finished products.

Information on the basic properties of the coconut frond's structure such as the specific gravity (sg), shrinkage and other physical properties has provided adequate basis for the effectual uses of coconut fronds and coconut fruit residues.

Aside from the basic understanding of the properties of the raw materials, the skills, creativity and craftsmanship on the part of the people who are involved in the job are crucial aspects in the production process. Some of the crafts and novelty items that can be produced are; all-purpose trays, trophies, flower vases and candle holders, chairs, dividers, plant boxes, table and dresser, etc.

The cost of processing the finished products varies depending on the type of items manufactured. The factors that affect the cost of production are the shape, design and size of the product, the machine and processes used as well as the labor and time involved in fabricating the said product. The more simple the product, the less time, labor and materials it requires, resulting to lower cost of production. The production cost estimates is about $50-60$ percent cheaper than the traditional wood materials.

Based on the current demands of the products, great marketing prospects could be expected not only for local market but especially for export. Thus, an increase in demand for the products can be projected if commercial venture is established. There is a different degree of demands for products such as coco-clock, coco-trays, frames, ash trays.

\section{Literature cited}

Arboleda, J.R. 1997. Industrial Application of Coconut Husk Products- The Development Experience of a Small Scale Industry. Technical Report. BUCALegaspi City.

Banzon, J.A. and J.R. Velasco. 1985. CoconutProduction and Utilization. PCRDF. Pasig, Metro Manila.

Magat, S.S. 1995. Techno Info-data on Coconut husk, Coir and Coir Dust. Leaflets. PCAARDB, Diliman, Quezon City

Palomar, R.N. and L.J. Penamora 2000. Development in the use of coconut farm residues for the manufacture of coirwood-cement board as alternative construction material. Coconut Research and Development (CORD) Journal, 16(2):56-66. 